"C2021 IEEE. Personal use of this material is permitted. Permission from IEEE must be obtained for all other uses, in any current or future media, including reprinting/republishing this material for advertising or promotional purposes, creating new collective works, for resale or redistribution to servers or lists, or reuse of any copyrighted component of this work in other works." 


\title{
TECHNOLOGY MANAGEMENT IN THE AGE OF DIGITAL TECHNOLOGIES
}

\author{
DilekCetindamar $^{\mathrm{a}}$ and Robert Phaal ${ }^{\mathrm{b}}$
}

\begin{abstract}
This paper focuses on the implications of digital technologies (DTs) for the technology management (TM) discipline. The study explores DT-induced changes through the lens of the widely used TM framework, where TM is a dynamic capability consisting of activities developing and implementing technologies as a source for competition. The findings help to offer an expansion of the TM framework in three major ways: (1) inclusion of orchestration as a new TM capability/activity, (2) integration of TM activities across multi-modal stakeholder interactions, and (3) emphasis on the critical role of TM professionals in carrying out TM activities. The proposed expanded version of the TM framework aims to provide a basis for future theoretical and applied research to advance understanding of the TM discipline.
\end{abstract}

\section{INTRODUCTION}

The digital era refers to the fourth industrial revolution, where organizations use new general-purpose technologies, including digital technologies (DTs) [1]. The majority of studies consider DTs consisting of a wide range of information and communication technologies, including artificial intelligence (AI), robotics, the Internet of things, autonomous vehicles, threedimensional (3D) printing, distributed ledger technology, and quantum computing [2]. The use of new technologies introduces challenges for organizations as a wide range of business operations are required to manage them effectively. Organizations transform by continuously changing their value creation, structure, and business model to keep up with DT-induced changes, which is widely known as "digital transformation" $[3,4,5]$.

Recent studies have already started to explore the radical impact of DTs in a few academic fields, highlighting the need to develop new theories in the digital age $[9,10,11]$. For example, a management study [8] considers the changes regarding the nature and purpose of dynamic capabilities due to the ubiquity of new DTs and proposes a "Digital Dynamic Capabilities theory." Another study [12] indicates how DTs radically change innovation management, pointing to the rise of "Digital Innovation Management." A study by Verganti et al. [13] explores AI's influence on the design management discipline in a similar vein.

Inspired by these studies on the impact of DTs on specific academic fields, this paper explores the implications of DTs for the technology management (TM) discipline. Drawing on the dynamic capabilities definition used by Helfat et al. [6], TM in this paper is defined as an organizational capacity to purposefully create, extend, or modify its technology base [14, 15].

\footnotetext{
a Dilek Cetindamar is with the University of Technology Sydney, Sydney, NSW 2007, Australia (corresponding author, e-mail: dilek.ck@uts.edu.au)

${ }^{\mathrm{b}}$ Robert Phaal is with the University of Cambridge, Cambridge, UK (e-mail: rob.phaal@eng.cam.ac.uk)
} 
That is why when technology base changes through the evolution of technologies, TM also evolves in parallel to the changes inherently taking place in technologies $[15,16]$.

Thus, this paper aims to shed light on the following research question: how do DTs change the TM discipline? To find an answer to this question, it becomes critical to understand the TM discipline and the nature of DTs. The present study is a conceptual paper like recent studies trying to grasp the DT-enabled changes in academic fields [7, 12, 13]. The basis of the study draws on a general TM framework used in the literature [8, 17, 18]. Based on the framework, we summarize significant DT-induced changes at the macro-level (business processes) by bringing together evidence from the extant literature. Then, we develop propositions regarding the implications of macro changes at the micro-level (TM activities) described in the framework.

Our study seeks to make two unique contributions to the TM literature. First, we offer an expansion to the general framework to improve our understanding of TM in the digital era. We suggest its expansion in three unique ways: including a new TM activity, considering multimodal stakeholder interactions, and highlighting the role of TM professionals. Second, our study highlights how many features of DTs allow bundling TM capabilities with greater benefits. This finding supports the recent studies aiming to expand the dynamic capabilities theory from observing individual capabilities to a group of capabilities. Our study also has a contribution to practice in the TM field. We draw the attention of TM managers, researchers, and practitioners to tackle the challenges of managing DTs, to equip TM professionals better to cope with them by improving their technical and soft digital skills such as digital literacy.

In the following three sections, the general TM framework will be summarized as a basis to explore the impact of DTs, leading to the presentation of a set of propositions to advance our understanding of DT-induced changes in the TM field and a summary of findings, contributions and limitations of the study, and research avenues for future studies.

\section{THE BACKGROUND: THE TM FRAMEWORK AND THE NATURE OF DTS}

\section{The TM framework}

The TM discipline has a history of 70 years [19], and Figure 1 shows one of the longstanding TM frameworks in the literature, which is based on the dynamic capabilities theory [18, 20]. The framework considers technology a resource, representing the technological knowledge that needs to be turned into products, processes, and services through the TM capabilities. TM capabilities are dynamic since they help induce change to an organizations' resource base [14]. Hence, companies achieve sustained competitive advantage through TM [6]. The TM framework prefers to call TM a set of activities since routines (i.e., repetitive patterns of activity), processes, capabilities, and activities are apparently used interchangeably [6, 20, 33].

The TM framework argues that TM activities are distributed and embedded in three core business processes - strategy, innovation, and operations, operating at the macro level in the firm. Effective TM aims to ensure that technological issues are incorporated appropriately in these processes to form a coherent and integrated system across and beyond specific business 
processes and activities. The framework emphasizes the dynamic nature of the knowledge flows between the macro-level (processes) and the micro-level (TM activities) [17, 20]. These knowledge flows appear as a push mechanism initiated by technological changes, technological changes, or a pull mechanism affected by customer demand.

Each TM activity is based on a specific technological capability. The generic version of the TM framework describes the six major groups of activities/capabilities, as follows [14]:

1) Identification includes search, auditing, data collection, and intelligence processes for technologies and markets and is necessary for technologies at all stages of development and market life cycle. This process area includes market changes as well as technological developments.

2) Selection takes account of company-level strategic issues, which requires a good grasp of strategic objectives and priorities developed at the business strategy level. Then, the selection process aligns technology-related decisions with business strategy.

3) Acquisition refers to how a firm obtains the technologies that are valuable for its business. The acquisition is based on the buy-collaborate-make decision. In other words, technologies might be developed internally, by some form of collaboration, or acquired from external developers. The management of acquisition differs based on the choice made.

4) Exploitation entails commercialization, but first, the expected benefits need to be realized through effective implementation, absorption, and operation of the technology within the firm. Technologies are assimilated through technology transfer either from $\mathrm{R} \& \mathrm{D}$ to manufacturing or from external company/partner to internal manufacturing department. Exploitation processes include incremental developments, process improvements, and marketing.

5) Protection includes activities ranging from patenting to staff retention that must be in place to protect intellectual assets within a firm, including the knowledge and expertise embedded in products and manufacturing systems.

6) Learning is a critical part of technological competency, involving reflections on technology projects and processes carried out within or outside the firm and their improvement. There is a strong link between this process and the broader field of knowledge management.

The generic nature of this framework comes from the fact that it is applicable irrespective of firm size, scope, industry, and structure. It implicitly assumes managers apply and adapt TM activities appropriately for the particular organizational context. Furthermore, the model takes account of the environment where the organization operates, as Figure 2 shows. TM activities of an organization try to strike an appropriate balance between market 'pull' (requirements) and technology 'push' (capabilities) that are operating external to the organization.

A final note on the TM framework is its treatment of interactions among TM activities. The framework foresees the process flows among them, but it does not generalize them in a deterministic way. Hence, TM activities might not necessarily follow a linear relationship, allowing any process to be the starting point that triggers many TM activities to take place. The flow of arrows shown in Figure 1 is for illustrative purposes rather than indicating a strictly linear relationship. 


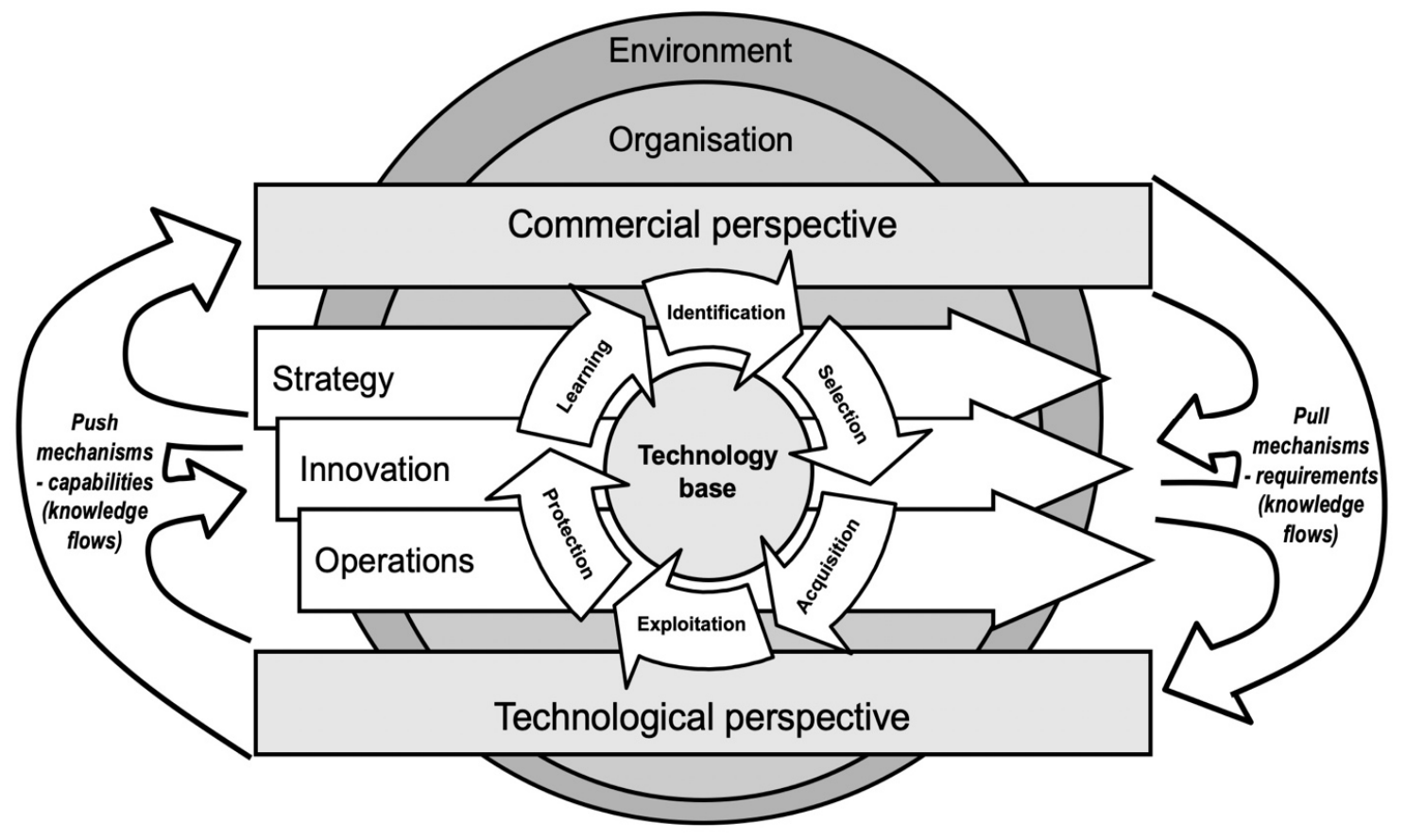

Figure 1. The TM Framework

Source: [14]

\section{The nature of DTs}

Technological changes radically affect the management of organizations $[1,16]$; thus, it is no surprise that the general TM framework faces some critical challenges in the digital era which require research attention. To put it simply, DTs comprise devices (such as smartphones and sensors), applications (such as computer software and information systems), and infrastructure (such as fixed-line and wireless networks). The key unique feature of DTs comes being general-purpose technologies, which refers to having much scope for improvement and being widely used [21].

Literature highlights the critical characteristics of DTs as follows [5, 9, 12, 22, 23, 24, 25]:

1) Reprogrammability of DT enables many products and services to have flexible and editable characteristics.

2) Homogenization of data makes it easy to build open and transferable systems.

3) Ubiquity and continuously increasing the use of digital technology provide a continuous flow of data.

4) Layered architecture facilitates digital products/services by assembling product-agnostic components from a set of heterogeneous layers (such as devices, networks, services, and contents) that use standardized interfaces [23].

5) Automation of data generation through many sources, including sensors and machine learning, increases data availability.

6) Creation of new business models and value propositions relying increasingly on the provision of services. 
7) Speed of development of software and devices requires flexible and agile management methods.

8) Intensified technological interactions and evolution of host-parasite technological systems, defined as "relationship of mutualistic symbiosis between a host (or master) technology and inter-related technologies to satisfy needs and/or to solve consequential problems of socioeconomic subjects over time." $[9, \mathrm{p} .1]$.

The unique features of DTs deliver many benefits and challenges to companies in using these general-purpose technologies. These benefits are instrumental in increasing firms' three core capacities: openness, affordance, and generativity [26]. Openness refers to open innovation practices, where DT can help decouple the form and function of products and services, modularize tasks at granular levels and automate data [26]. These features allow innovators to be anywhere and still cooperate for digital product and service design and development [2]. Affordance refers to action possibilities or opportunities for action; thus, DT's realization depends on how technology is created by different actors [12]. That is why the same digital artifact, digital platform, or digital infrastructure can lead to different innovations depending on the user or its context. Generativity refers to the capacity exhibited by DTs to produce unprompted change through the mechanisms of blending or recombination where many stakeholders are involved [12]. The designers of components in a layered modular architecture cannot fully know how the components will be used [16, 23, 27].

Because of these capacities, DT has the power to transform companies and industries on a large scale $[16,21,37]$. DTs have already created digital transformations across various industries, particularly healthcare, telecommunications, automotive, banking, and manufacturing sectors $[28,29]$. Digital transformation refers to a process of improving an entity by triggering significant changes to its properties through combinations of information, computing, communication, and connectivity technologies [4]. What is different in the case of DTs compared to other general-purpose technologies such as biotechnology is that DTs create an ongoing process of using new DTs in everyday organizational life $[8,30]$. They enable innovation practices, improved designs, and new business models and shapes how organizations create value on the Internet [4]. In other words, DTs continuously offer opportunities for companies.

Furthermore, a key distinguishing feature of DT compared to other technologies is the pace of development [25]. For software, innovation cycles can take days and weeks, with the long-term being a year or two. For electronics (hardware), innovation cycles are typically months to a year, with the long-term being perhaps three years. Innovation cycles can take many years for infrastructure and materials, with the long-term measured in decades. Thus, the management methods used to manage DT need to account for both the pace of development and synchronization issues across technologies and systems [31].

In sum, the continuous and rapid DT-enabled transformations exceed any single organization's borders and transform simple products/services/industries into complex ones. The TM field needs to examine the impact of DT on business processes and TM activities to cope with the impact of DT-enabled transformations on business processes and TM activities. 


\section{THE NEED FOR THE EXPANSION OF THE TM FRAMEWORK}

The continuous and fast transformations induced by DTs bring in numerous macro-level changes in innovation, operations, and strategy processes that ultimately trigger micro-level changes in how TM practices are carried. After all, the macro-level changes of processes and micro-level changes of activities are mutually constitutive and shape each other [32]. Hence, the following paragraphs summarize findings from the literature showing the impact of DTs on each process and its consecutive effect on TM. Based on the analysis, we propose an expanded version of the TM framework to accommodate DTs' impact and navigate TM professionals in a digital future.

\section{Innovation}

Regarding innovation, several studies highlight radical changes taking place in innovation processes. DTs allow efficient open innovation practices. An example is Amazon's Kindle, a digital book device [23], which exemplifies how a product and service bundle has become a reality through the computer industry's complex ecosystem. The Kindle's ecosystem consists of consumer electronics, internet search, online retailing, book retailing, telecommunications, and publishing firms' alliances. The success of such open innovation practices requires a capability of designing dynamic problem-solution pairs, defined as a set of couplings between needs, user affordances, digital artifact features, and related contexts [12]. In particular, it is argued that AI could efficiently perform problem solutions while allowing professionals to focus on the problem finding process [13]. By doing so, AI-human cooperation could enhance opportunities for open innovation solutions.

Additionally, DT becomes a crucial enabler of the orchestration of problem-solution pairs among complex and dynamic sets of actors and processes involved in innovation processes. This ability comes from its generativity power. Digital technology, such as artifacts and platforms, forms the base for intensified interaction of diverse innovation agents. These interactions foster innovative socio-cognitive sensemaking that is defined as simultaneously making sense of individual innovator's cognition and the innovator's social system, comprising collectives of organizations and individuals [12]. Furthermore, the sensemaking ability helps to contextualize the use of DTs [7]. In other words, it becomes possible to stay in touch with the practical context in which information systems are used and data is utilized for a service or product. For example, Google's designers cannot fully anticipate possible ways to use Google Maps as a component. Thus a hotel might use Google Maps as a service to its customers while a mobility company might integrate it into a self-driving car to support navigation [13]. The users of other companies make sense of any digital component and adopt it in a particular context.

Changes in innovation processes also entail improved stakeholder interactions. Digital technologies produce unprompted change through the mechanisms of blending or recombination where many stakeholders are involved $[12,16]$. Such technologies easily facilitate multi-modal interaction across a wide variety of stakeholders through digital platforms. A platform is a combination of hardware and software that provides standards, interfaces, and rules that allow providers of complementary products/services to add value and interact with each other and/or users. Collectively, platform innovator(s) and complementary partners constitute an ecosystem 
that depends on continued innovation and maintenance of the platform by its owner(s) for success [33, p.10]. For example, a smart bulb, integrated by sensors, can be connected to other objects such as Google's Nest and a smart doorbell. However, more importantly, it could become part of a security system, turn into a motion-sensing device, and feed live cameras within a house or a street [34].

This kind of increased connectivity among objects, assets, systems, and people points to a need for a new TM capability to manage a wide variety of stakeholders [4] or to integrate multiple stakeholders [13]. We call this an orchestration activity, from [4, p.1395]: "orchestration activity directed toward the introduction and modification of products; resources and capabilities; business models. They can be internal (within the firm) or external (across firms, e.g., through alliances and partnerships)". In other words, companies' orchestration ability helps them be part of a digital product platform [23]. This capability/activity helps firms to create new meanings for their products and services and to redefine products through an active reshaping of the product ecology on a real-time basis [12]. One example is Apple's iOS service system, shaped and reshaped through distributed tuning involving actions of a network of heterogeneous actors and artifacts [35]. Hence, we claim that:

- Proposition 1: DTs necessitate an orchestration capability to manage multi-modal interaction with a wide variety of stakeholders.

\section{Operations}

Regarding operations, DT seems to bring three critical changes to the operation process. First, DT helps to modularize tasks [24]: specifying the details of inputs and outputs of digital tasks, defining modules of tasks, and building their standardized interfaces. Both modular architectures and learning algorithms enable organizations to divide, allocate and integrate tasks. Learning algorithms are already automating administrative coordination by managing task decomposition and integration [5]. On top of that, the inputs, processes, and outcomes associated with digital tasks can be tracked and traced at a granular level, along with contextual parameters. As recent studies point out, working in independent, modular, and mobile arrangements enables the development of practices that continually construct productive spatial, temporal, social, and material contexts for work [36]. Second, DT allows the formation of a doubly distributed organizing logic, defined as [23, p. 730]: "It is doubly distributed because (a) the control over product components is distributed across multiple firms, and (b) the product knowledge is distributed across heterogeneous disciplines and communities." This organizing logic is based on generativity from the unbounded mix-and-match capability of heterogeneous resources across layers facilitated by DT. For example, cloud technologies allow the leverage of ubiquitous availability of a broad and varying range of digital capabilities. Third, DT enables organizational adaptiveness by providing infrastructure functionality [37]. Adaptiveness results from changes in business processes that allow the exploitation of diverse opportunities, overcome organizational and technological boundaries through integrated systems, and deploy new processes such as cloud-based services. These adaptive capabilities reinforce the flexibility to scale and maintain organizational resilience to radical changes in markets and technologies. 
Changes taking place in operations result in higher performance for TM activities. Studies highlight how DTs provide the opportunity to continually improve all types of TM activities' efficiency and effectiveness through communication platforms and analytic [38]. For example, DT makes it easy to manage open and transferable systems and increases products and processes' flexibility. Similarly, learning drives the dynamic and continuous improvement into TM. Many DT features help TM practitioners flow knowledge among projects and between different units and internal or external organizations. Learning activity seems to flourish thanks to the availability of endless support through big data and AI. In particular, machine learning speeds up the learning process and turns it into a continuously evolving form [13]. As shown in a bank in South Africa, continuous learning capability enables a conducive environment for tacit and codified knowledge to be transferred among peers and external stakeholder involvement [38].

The dynamic capabilities literature presents many studies showing a linear performance improvement due to these capabilities, regardless of the category of these capabilities [57]. What is interesting with DTs that these technologies' openness and generativity features allow companies to enjoy the benefits of bringing together capabilities of various stakeholders as a bundle rather than from isolated capabilities of individual companies per se [6]. In fact, even individual companies benefit from the synergies of bundling diverse capabilities together at the company level. For example, an empirical study shows how various manufacturing capabilities bundle together and improve company performance [58]. It is natural to expect that collaborations with stakeholders in managing technologies could generate positive outcomes. Hence, we propose that:

- Proposition 2: DTs increase the bundling of TM activities across stakeholders, resulting in higher levels of efficiency and effectiveness of all types of TM activities.

\section{Strategy}

Regarding strategy, DTs offer several affordances for the whole strategy process. Some studies mainly describe digital transformation as an ongoing process of using new DT to enable an organization's strategic renewal [8]. Hence, the impact of DT on strategy happens through decision-making and business models. DT impacts strategic decision-making processes in many ways. For example, big data analytics "focus on very large, unstructured and fast-moving data" [39, p. 10], and hence they enable managers to analyze and interpret any digital information. Technical and analytical advancements in big data analytics enable digital products and services, and they are also crucial for developing sophisticated AI, cognitive computing capabilities, and business intelligence [40]. All these technologies collaboratively improve the effectiveness and efficiency of decision-making for managers.

In terms of business models, DTs expand the horizon of strategy processes to digital platform-based ecosystems. For example, platform-based strategies require platform leaders to engage with the design, management, and transformation of ecosystems as conditions change $[39,41]$. The case study of Alibaba shows that platform providers have to mentor, facilitate and make rules for their platforms to facilitate the engagement of small, medium-sized enterprises as contributors of platforms [41]. In other words, new business models around platforms need a 
high level of strategic effort in terms of communication and coordination with platform stakeholders. Companies can utilize platforms for their business models since DTs have a layered architecture consisting of devices, networks, services, and contents. Literature suggests different platforms ranging from transactions to innovation platforms [33]. For example, a transaction platform facilitates exchanges of consumers and firms such as eBay, and a digital transaction platform leverages the knowledge shared by its users, such as Facebook [42]. Many examples from Apple, Google, and Samsung show how platforms harness technological affordances to facilitate entrepreneurial opportunity pursuit [34].

The changes in strategy processes highlight the role of TM professionals. Even though DTs tend to automate and carry out many activities that humans can, there are certain areas where they need human intervention for several reasons [7]. TM professionals realize daily TM practices not as simple automata but as innovative interpreters of these practices. Thus, the active involvement of TM professionals could unfold the affordances and generativity of DTs. As studies show, there are soft skills that AI algorithms cannot replace. For example, Verganti [13, p. 225] points out that "an algorithm that has been created to solve a problem cannot refuse to solve it; it cannot pull the plug (unless this trigger is already incorporated in its code). A human can. She can avoid to create, if it does not make sense, morally, emotionally, or by intrinsic motivation." Discussions on trust, ethics, and fairness are increasingly becoming critical concerns about AI algorithms [43]. For example, AI algorithms find patterns within datasets that reflect implicit biases such as gender and, in so doing, emphasize and reinforce these biases as global truth in employment software [44]. The related problem is that data are becoming decontextualized, which happens when data comes from many information systems and digital resources of various kinds [7]. That is why there are efforts to make sense of the data for further processing and delivering socially meaningful messages based on that data, such as data mining and explainable AI. However, all these concerns strongly underline the role of humans in decision-making $[5,59]$, leading us to suggest:

- Proposition 3: DTs increase the role of TM professionals as the agents of actualization of dynamic capabilities.

The third proposition demands a closer examination of TM professionals to grasp how DTs might affect their role in managing technologies. Automation of operations increases the demand for soft, generic, and transferable skills, with an increasing emphasis on computer skills to facilitate significant work $[15,33,45]$. TM professionals are not just based at corporate headquarters anymore, but they work within a highly mechanized and digitalized work environment. For example, a service engineer working on a faulty hydraulic pump drilling rig in the Gulf of Mexico downloads service reports from colleagues worldwide on their solutions to a pump failure [46]. Furthermore, automation is not limited to production but is widely applied to services. Some famous examples can found in the entertainment industry, where companies such as Netflix and Airbnb utilize DT to the ultimate automation levels where computers carry out most decision-making [13]. These changes call for highly information technology-related sets of skills. For example, in robotic surgeries, trainees can no longer assist surgeons directly at the operating table and work around the surgical profession's norms and conventions [5]. TM professionals will learn how to work with various DTs, such as AI-based algorithms, like many occupational groups. 
However, digital skills are not limited to technical knowledge. TM professionals have to have a wide range of soft skills to know what the technology is, how to use it, when to use it, and why. One such soft skill is digital literacy, referring to digital knowledge, competence, and learning needed to carry out daily work using DTs [47, 48]. The expectation is that digitally literate TM professionals could conceive possibilities arising from DT, put them into use, learn from interactions to adapt their behavior, and find new ways of using technologies through their daily practices $[32,45]$. That is why studies point out employees' digital literacy as critical for organizations during their digital transformations [4, 22, 47].

One final remark about TM professionals is their increased role in working with stakeholder organizations. DTs allow the immediate exchange of explicit knowledge, but TM professionals' soft skills could make a difference working with the flow of tacit knowledge among stakeholders, improving DTs' utilization [46]. Accordingly, TM professionals might develop a "shared digital identity" defined as "the collective self-concept(s) of an in-group towards the creation, application, development, and emergence of digital technology built on a sense of community, enthusiasm, being part of something special and common values and norms" [49, p. 81]. The example of knowledge flow among stakeholders of a digital ecosystem in the 3D printing industry shows how DTs have managed to form a digital identity among their employees for effective knowledge flow within the ecosystem.

As identified above through propositions 1 to 3 , the general-purpose features of DTs highlight the alignment needed in the TM field to keep pace with the continuous form of DTenabled transformations crossing organizational borders. Hence, we argue that the existing TM framework needs an extension to accommodate the challenges induced by DTs. Figure 2 shows our proposed expanded version to accommodate the significant changes induced by DTs.

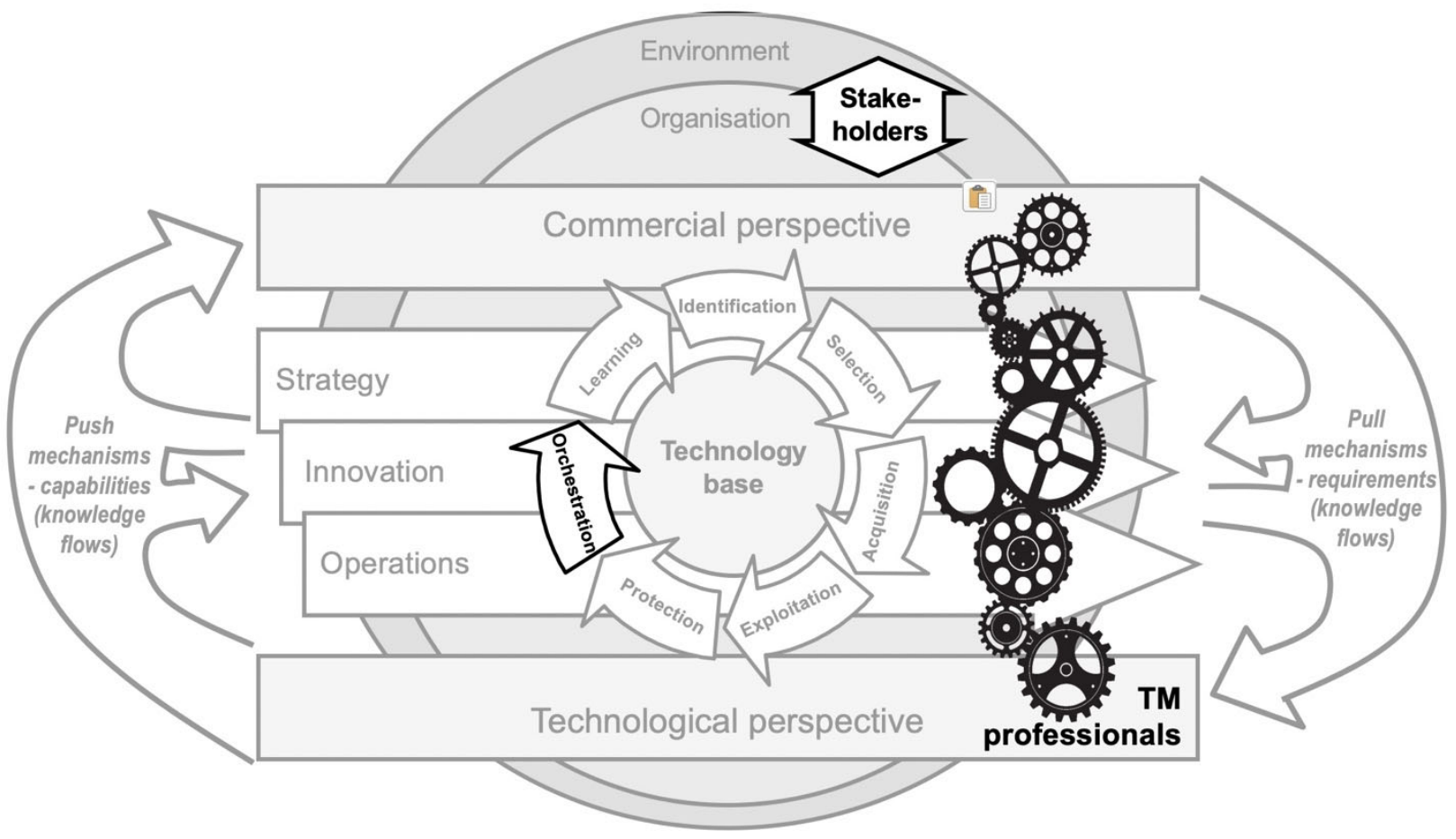


Figure 2. Expanded TM model in the digital era (three expansions highlighted in bold).

Note: Stakeholders include customers, users, suppliers, competitors, universities, government agencies, communities, etc.

Source: Authors.

Overall, we offer three expansions to the original model based on the three propositions respectively:

1) TM activities are expanded with the inclusion of a new process capability, orchestration (Proposition 1).

2) Stakeholder interactions between organizations are highlighted, outside-in and inside-out. These two alignments within the framework facilitate TM activities between organizations through intensive multi-modal stakeholder interactions (Proposition 2).

3) The critical role of professionals in carrying out TM activities is emphasized. Increased complexity and the continuous nature of DT transformations require more and more involvement of TM professionals within the organization and outside the organization (Proposition 3).

\section{CONTRIBUTIONS AND CONCLUDING REMARKS}

With DTs being general-purpose technologies with an almost unlimited area of applications, TM scholars face the responsibility of contextualizing DTs to move the discipline forward toward a more specific and in-depth understanding of these technologies. Similar efforts have been carried out in adjacent disciplines such as design [13] and innovation management [12]. This conceptual paper explores the impact of DTs on the TM discipline by using the generic TM framework available in the literature. .

Our observations underline changes in business processes (macro-level) and TM activities (micro-level). Regarding business processes, the study highlights how DT allows agile modularization arrangements and contributes to the efficiency and effectiveness of business processes thanks to the bundling capabilities. Regarding the TM activities, DT improves the original set of activities, identification, selection, acquisition, exploitation, protection, and learning. However, DT points out the lack of capability that is required to deal with stakeholder management. Hence, we recommend orchestration as a new capability to be included in the TM model [15]. This capability embodies combinatorial skills [26] and resonates well with building the organizations' generativity capacity [4].

Our study further shows that TM professionals are the actors realizing the TM activities daily as innovative interpreters of practices and DTs. As widely discussed in the management literature, the critical role of professionals in carrying out strategic activities need to be recognized [59]. Recognizing their role explicitly could help managers consider sought-after TM professionals' technical skills complemented with soft, generic, and transferable digital skills [15]. Among those skills, digital literacy seems to stand out as an essential skill for all TM professionals, regardless of their employment status as engineers or managers. This skill makes the foundation for TM professionals who face more and more challenges related to mindsets that could align with digital workplaces [5]. TM professionals recognize affordances and capture them through sensemaking skills. Hence, the management of DT brings forward the critical role 
of TM practitioners who could combine their technology and soft skills to align with the continuous form of DT-enabled transformation crossing the borders of individual organizations.

\section{Implications for theory}

Our conceptual work contributes to the TM field in two ways. First, the study extends the TM field by offering an extended version of the generic TM model [52]. To our knowledge, the proposed framework is the first theoretical effort to capture TM's evolution in our discipline under the influence of DTs. The macro-level changes across business processes point out three main changes at the micro-level TM activities. These are the addition of a new TM activity, the integration of TM activities along with multi-modal stakeholder interactions, and the highlight of TM professionals' critical role in managing digital technologies. We believe that the emphasis on TM professionals and stakeholders could help link the TM field to organizational studies to understand the entangled development of technologies within social contexts [32].

Second, our study highlights how DTs could allow bundling of TM capabilities across stakeholders with greater benefits. By doing so, the study joins the recent studies interested in advancing dynamic capabilities theory towards the analysis of a group of capabilities rather than individual ones [58]. This line of research could bring a nuanced understanding of capabilities and their interactions within the TM field.

\section{Implications for TM practice}

Concerning practice, we draw TM managers' and practitioners' attention to the changes taking place at the macro (process) and micro (activity) levels. Our paper informs TM professionals of the significant challenges and opportunities in business processes due to DT's diffusion at the macro-level. This paper highlights the need for agility and new skills such as digital literacy needed to run effective and efficient TM activities [53]. In addition, we emphasize that TM professionals should adopt new mindsets that can facilitate their complex interactions with multiple stakeholders. In short, technologies are dynamic and emergent due to their recursive development through interactions in the business processes and TM activities in a situated environment [30, 32]. Such an understanding enables valuable, practical insights into how TM professionals should introduce and manage DTs in their organizations.

Further, understanding digital literacy could explicitly give managers a tool to understand their workforce's capacity to improve their TM activities. Literature shows that prioritizing employees' focus on organizational practices results in innovations [54]. Many work practices in digital organizations include team-based design, information sharing, aggregate compensation strategy, flexible job design, and employee training [47]. In order to carry out this kind of activity, companies need to assess their TM capabilities. Also, they need to understand gaps in their digital capacities to design and implement their work practices allowing the utilization of DTs.

\section{Limitations and suggestions for future studies}

Our study is prone to six key limitations, each bringing opportunities for future research. We hope that the following detailed suggestions could initiate a discussion to advance our understanding of DT-enabled changes and accommodate them within the TM discipline. 
First, this paper is a conceptual contribution, drawing from literature and using the lens of TM practice. The discussion in this paper aims to draw the attention of TM academicians and TM professionals on how DTs influence the discipline. In the future, studies might be interested in reinventing TM at the theoretical level, similar to the efforts made in the innovation management field $[12,60]$. However, future studies should specifically conduct empirical research to assess the changes taking place at digital enterprises and their impact on TM. These empirical studies could shed light on the complex interactions among DTs' material characteristics with their context to shed light on the relationship between DTs and TM activities [32].

Second, our research has not delved into any specific digital technology. This paper aims to capture DT-enabled changes at companies as presented in the extant literature, which is highly limited to general DT discussions [4]. A few studies explore particular technology areas, such as AI in the entertainment company Netflix [13], cloud technologies [40], and digital threedimensional (3-D) $[49,55]$. These studies are diverse in nature, and it is difficult to draw out general implications for the TM field. This gap presents a significant opportunity for TM researchers to study specific DTs and related changes in TM practice for in-depth studies of specific DTs. A compilation of these individual technologies might pave the way for comparisons of findings and enrich their management.

Third, this study adopts a company perspective, with the general TM framework developed to understand how TM functions within firms [14]. Hence, the analysis and expanded framework are limited to company settings. However, many organizations such as governments and universities also run TM activities. Future studies could attempt to understand their practices and drive new models applicable in various organizational contexts.

Fourth, the paper does not cover all aspects of the implications of DT-induced changes. Even though the paper briefly mentions some negative impacts of DTs, such as unemployment and ethics, the paper does not cover the negative impact of DTs in-depth [43, 44]. Another sensitive issue concerns the impact of DT at the individual level for engineers and TM managers. Recent studies clearly show the radical changes experienced by employees in terms of identity and wellbeing $[5,56]$. These neglected topics about the broader implications of DT could be another avenue of research for TM researchers to develop a better and balanced understanding of the impact of DTs on the TM discipline and its professionals.

Fifth, experience during the COVID-19 pandemic has shown that future workplaces will become increasingly hybrid in form, where employees will work in independent, modular, and mobile arrangements. These kinds of highly possible changes enabled by digital technologies could eventually change productive spatial, temporal, social, and material contexts for work in a continuous way [29, 36]. However, little is known about the different professional implications of these transformative practices. Future studies could tackle this field to develop an in-depth understanding of how the TM profession might change in the digital era.

The final limitation of this research is its focus on digital technologies. It does not have a comparative analysis of the impact of many general-purpose technologies such as DT versus nanotechnology. Historical studies in the evolution of technologies many benefits of such 
comparative analysis [16]. This line of research could bring nuances in managing specific technologies and advance the TM field. Future studies could conduct a comparative analysis based on accumulated examples.

As a final remark, we want to invite TM scholars to build common definitions and frameworks to advance our discipline. It is of utmost importance to have sound TM frameworks that could help organizations implement, maintain, and improve TM systems. Only such a collaborative effort could succeed what innovation management scholars have achieved, a universal framework for innovation management called the ISO 56000 established in 2019 by International Organization for Standardization.

\section{REFERENCES}

[1] K. Schwab, The Fourth Industrial Revolution, Danvers, MA: Crown Business, 2017.

[2] P. C. Verhoef, T. Broekhuizen, Y. Bart, A. Bhattacharya, J. Q. Dong, N. Fabian, \& M. Haenlein, "Digital transformation: A multidisciplinary reflection and research agenda," Journal of Business Research, vol. 122, pp. 889-901, 2021.

[3] C. Matt, T. Hess, \& A. Benlian, "Digital transformation strategies," Business \& Information Systems Engineering, vol. 57, no. 5, pp. 339-43, 2015.

[4] G. Vial, "Understanding digital transformation: A review and a research agenda," The Journal of Strategic Information Systems, vol. 28, no. 2, pp. 118-44, 2019.

[5] S. Faraj, S. Pachidi, \& K. Sayegha, "Working and organizing in the age of the learning algorithm," Information and Organization, vol. 28, pp. 62-70, 2018.

[6] Helfat, C.E., S. Finkelstein, W. Mitchell, M.A. Peteraf, D.J. Teece, S.G. Winter. Dynamic Capabilities: Understanding strategic change in organizations. Malden, MA: Blackwell Publishing, 2007.

[7] K. Grace, J. Salvatier, A. Dafoe, B. Zhang, \& O. Evans, "When will AI exceed human performance? Evidence from AI experts," Journal of Artificial Intelligence Research, 2018. https://doi.org/10.1613/jair.1.11222.

[8] K.S. Warner \& M. Wäger, "Building dynamic capabilities for digital transformation: An ongoing process of strategic renewal," Long Range Planning, vol. 52, no. 3, pp. 326-49, 2019.

[9] M. Coccia \& J. Watts, "A theory of the evolution of technology: Technological parasitism and the implications for innovation management." Journal of Engineering and Technology Management, vol. 55, 101552, 2020. DOI: https://doi.org/10.1016/j.jengtecman.2019.11.003

[10] B. Hinings, T. Gegenhuber, \& R. Greenwood, "Digital innovation and transformation: An institutional perspective," Information and Organization, vol. 28, pp. 52-61, 2018. 
[11] M. S. Feldman \& W. J. Orlikowski, "Theorizing practice and practicing theory," Organization Science, vol. 22, no. 5, 1121-367, 2011.

[12] S. Nambisan, K. Lyytinen, A. Majchrzak, \& M. Song, "Digital Innovation Management: Reinventing innovation management research in a digital world," MIS Quarterly, vol. 41 no. 1, pp. 223-38, 2017.

[13] R. Verganti, L. Vendraminelli, \& M. Iansiti, "Innovation and design in the age of artificial intelligence," Journal of Product Innovation Management, vol. 37, no. 3, pp. 212-27, 2020.

[14] D. Cetindamar, R. Phaal, \& D. Probert, Technology Management Activities and Tools, London: Palgrave/Macmillan. 2st Edition, 2016.

[15] D. Cetindamar, R. Phaal, \& D. Probert, "Technology management as a profession and the challenges ahead", Journal of Engineering and Technology Management, vol. 41, pp. 1-13, 2016.

[16] M. Coccia M., "A theory of the general causes of long waves: War, general purpose technologies, and economic change," Technological Forecasting \& Social Change, vol. 128, pp. 287-295, 2018.

[17] M.J. Gregory, "Technology management-a process approach," Proc. of the Institution of Mechanical Engineers, vol. 209, pp. 347-356, 1995.

[18] R. Phaal, C.J. Farrukh, \& D.R. Probert, "A framework for supporting the management of technological knowledge," International Journal of Technology Management, vol. 27, no. 1, pp. $1-15,2004$.

[19] D. Cetindamar, T. Lammers, D. Kocaoglu, \& Y. Zhang, "An anniversary tribute to PICMET - 1989-2018 bibliometric review," IEEE Transactions on Engineering Management, vol. 68, no. 2, pp. 612-627, 2021.

[20] D. Cetindamar, R. Phaal, \& D. Probert, "Understanding technology management as a dynamic capability: A framework for technology management activities," Technovation, vol. 29, no. 4, pp. 237-246, 2009.

[21] R.G. Lipsey, C.T. Bekar, and K.I. Carlaw, "What requires explanation? In: E. Helpman (Ed.), General Purpose Technologies and Long-term Economic Growth. MIT Press, Cambridge, MA, pp. 15-54, 1998.

[22] E. Autio, S. Nambisan, L.D. Thomas, \& M. Wright, "Digital affordances, spatial affordances, and the genesis of entrepreneurial ecosystems," Strategic Entrepreneurship Journal, vol. 12, no. 1, pp. 72-95, 2018. 
[23] Y. Yoo, O. Henfridsson, \& K. Lyytinen, "The new organizing logic of digital innovation: An agenda for information systems research," Information Systems Research, vol. 21, no. 4, pp. 724-35, 2010.

[24] Editors. "The digital workforce and the workplace of the future," Academy of Management Journal, vol. 59, no. 3, pp. 731-39, 2016.

[25] M. Routley, R. Phaal, \& D. Probert, "Exploring industry dynamics and interactions," Technological Forecasting \& Social Change, vol. 80, no. 6, pp. 1147-61, 2013.

[26] S. Nambisan, M. Wright, \& M. Feldman, "The digital transformation of innovation and entrepreneurship: Progress, challenges and key themes," Research Policy, vol. 48, 103773, 2019.

[27] C.I.V. Kerr, L. Mortara, R. Phaal, \& D.R. Probert, "A conceptual model for technology intelligence," International Journal of Technology Intelligence and Planning, vol. 2, no. 1, pp. 73-93, 2006.

[28] A. Nadeem, B. Abedin, N. Cerpa, \& E. Chew, "Digital transformation \& digital business strategy in electronic commerce-the role of organizational capabilities," Journal of Theoretical and Applied Electronic Commerce Research, vol. 13, no. 2, pp. i-viii, 2018.

[29] L. Muñoz-Pascual, C. Curado, \& J. Galende, "How does the use of information technologies affect the adoption of environmental practices in SMEs? A mixed-methods approach," Review of Managerial Science, vol. 15, pp. 75-102, 2021.

[30] B.W. Arthur, The Nature of Technology. What it is and How It Evolves. Allen LanePenguin Books, London, 2009.

[31] S. Vinayavekhin \& R. Phaal, "Synchronization in strategic planning: A roadmapping framework," International Journal of Innovation and Technology Management, vol. 16, no. 6, 21 pages, 2019. https://doi.org/10.1142/S0219877019500445

[32] W.J. Orlikowski and S.V. Scott, "Sociomateriality: Challenging the separation of technology, work and organization," Annals of the Academy of Management, vol. 2, no. 1, pp. 433-74, 2008.

[33] D.J. Teece \& G. Linden, "Business models, value capture, and the digital enterprise," Journal of Organization Design, vol. 6, paper no. 8, 2017. https://doi.org/10.1186/s41469-0170018-x

[34] M. Subramaniam, B. Iyer \& V. Venkatraman, "Competing in digital ecosystems," Business Horizons, vol. 62, pp. 83-94, 2019.

[35] B. Eaton, S., Elaluf-Calderwood, C. Sørensen, "Distributed tuning of boundary resources: The case of Apple's IOs service system," MIS Quarterly, vol. 39, no. 1, pp. 217-243, 2015. 
[36] M.H. Jarrahi \& L. Thomson, "The interplay between information practices and information context: The case of mobile knowledge workers," Journal of the Association for Information Science and Technology, vol. 68, no. 5, pp. 1073-89, 2017.

[37] T.C. Li \& Y.E. Chan, "Dynamic information technology capability: Concept definition and framework development," The Journal of Strategic Information Systems, vol. 28, no. 4,101575, 2019.

[38] C.I.V. Kerr, L. Mortara, R. Phaal, \& D.R. Probert, "A conceptual model for technology intelligence," International Journal of Technology Intelligence and Planning, vol. 2, no. 1, pp. 73-93, 2006.

[39] R. Davenport, Big Data at Work: Dispelling the Myths, Uncovering the Opportunities. Boston: Harvard Business Review Press, 2014.

[40] C. Loebbecke \& A. Picot, "Reflections on societal and business model transformation arising from digitization and big data analytics: A research agenda," Journal of Strategic Information Systems, vol. 24, pp. 149-57, 2015.

[41] C.E. Helfat \& R.S. Raubitschek, "Dynamic and integrative capabilities for profiting from innovation in digital platform-based ecosystems," Research Policy, 47 (8), 1391-99, 2018.

[42] S. Zuboff, "Big other: Surveillance capitalism and the prospects of an information civilization," Journal of Information Technology, vol. 30, pp. 75-89, 2015.

[43] V.G. Konovalova \& A.E. Mitrofanova, "Social and ethical problems of digital technologies application in human resource management," Lecture Notes in Networks and Systems, 133, pp. 735-742, 2021.

[44] A. Howard \& J. Borenstein, "The ugly truth about ourselves and our robot creations: the problem of bias and social inequity," Science and Engineering Ethics, vol. 24, no. 5, pp. 15211536, 2018.

[45] M. White, "Digital workplaces: Vision and reality," Business Information Review, vol. 29, no. 4, pp. 205-14, 2012.

[46] V.O. Gekara \& V.X.T. Nguyen, "New technologies and the transformation of work and skills: A study of computerisation and automation of Australian container terminals," New Technology, Work and Employment, vol. 33, no. 3, pp. 219-33, 2018.

[47] D. Cetindamar \& A. Babak, "Understanding the role of employees in digital transformation: Conceptualization of digital literacy of employees as a multi-dimensional organizational affordance", Journal of Enterprise Information Management, 2020. https://doi.org/10.1108/JEIM-01-2020-0010. 
[48] A. Littlejohn, H. Beetham, \& L. Mcgill, "Learning at the digital frontier: A review of digital literacies in theory and practice," Journal of Computer Assisted Learning, vol. 28, no. 6, pp. 54756, 2012.

[49] R. Bouncken \& R. Barwinski, "Shared digital identity and rich knowledge ties in global 3D printing-A drizzle in the clouds?” Global Strategy Journal, vol. 11, pp. 81-108, 2021.

[50] S. Konlechner, B. Müller, \& W. H. Güttel, "A dynamic capabilities perspective on managing technological change: A review, framework and research agenda," International Journal of Technology Management, vol. 76, no. 3/4, pp. 188-213, 2018.

[51] R. Pershina, B. Soppe, \& T.M. Thune, "Bridging analog and digital expertise: Cross-domain collaboration and boundary-spanning tools in the creation of digital innovation," Research Policy, vol. 48, no. 9,103819, 2019.

[52] C. Kerr, C. Farrukh, R. Phaal, \& D.R. Probert, "Key principles for developing industrially relevant strategic technology management toolkits," Technological Forecasting \& Social Change, vol. 80, pp. 1050-70, 2013.

[53] A. Singh \& T. Hess, "How chief digital officers promote the digital transformation of their companies," MIS Quarterly Executive, vol. 16, no. 1, pp. 1-17. 2017.

[54] R. Batt \& A.J.S. Colvin, "An employment systems approach to turnover: human resources practices, quits, dismissals, and performance," The Academy of Management Journal, vol. 54, no. 4, pp. 695-717, 2011.

[55] Jr. R.J. Boland, K. Lyytinen, \& Y. Yoo, "Wakes of innovation in project networks: The case of digital 3-D representations in architecture, engineering, and construction," Organization Science, vol. 18, no. 4, pp. 631-47, 2007.

[56] M. Carter, S. Petter, V. Grover, \& J.B. Thatcher, "Information technology identity: A key determinant of IT feature and exploratory usage." MIS Quarterly, vol. 44, no. 3, pp. 983-1021, 2020 .

[57] A. Karna, A. Richter, \& E. Riesenkampff, "Revisiting the role of the environment in the capabilities-financial performance relationship: A meta-analysis." Strategic Management Journal, vol. 37, no. 6, pp. 1154-73, 2016.

[58] Waleczek, P., T. von den Driesch, T.C. Flatten,. \& M. Brettel, "On the dynamic bundles behind operations management and research and development." European Management Journal, vol. 37 , no. 2, pp. 175-87, 2019.

[59] R. Whittington, "Completing the practice turn in strategy research." Organization Studies, vol. 27, no. 5, pp. 613-34, 2006. 
[60] Hutchinson, P., "Reinventing innovation management: The impact of self-innovating Artificial Intelligence." IEEE Transactions on Engineering Management, vol. 68, no. 2, pp. 628639, 2021.

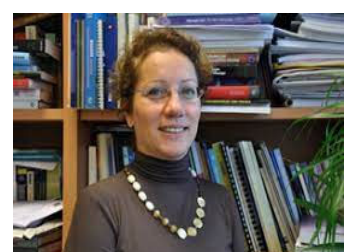

Dilek Cetindamar is a professor of Contemporary Technology Management at the University of Technology Sydney, Australia. She has more than 220 publications, including 9 books. She received PICMET Fellow Award in 2019, best book award from International Association for Management of Technology in 2012, and an "encouragement award" from the Turkish Academy of Sciences in 2003. She is specialized in Innovation \& Technology Management. She received a PhD in Management in 1995 from Istanbul Technical University, She received MA in Economics and BS in Industrial Engineering in 1992 and 1989 respectively from Bogazici University, Turkey.

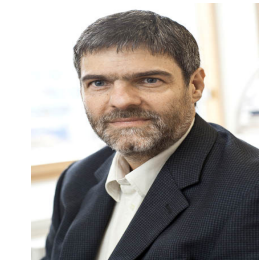

Dr Robert Phaal joined the Centre for Technology Management at the University of Cambridge in 1997, part of the Department of Engineering. As a Director of Research, he conducts research in the field of strategic technology and innovation management. Areas of interest include roadmapping, the emergence of technology-based industry, technology evaluation, and the development of practical management tools. Rob has a mechanical engineering background, with a $\mathrm{PhD}$ in computational mechanics from the University of Cambridge in 1990. He is a Chartered Engineer and Member of the IET, with industrial experience in technical consulting, contract research and software development. 